\title{
Perspective
}

PERSPECTIVE Actualité en histoire de l'art

Comptes rendus | 2012

Aufbruch in die Gotik: Der Magdeburger Dom und die späte Stauferzeit, Landesausstellung Sachsen-Anhalt aus Anlass des 800. Domjubiläums, 2 vol., Matthias Puhle éd., (cat. expo., Magdeburg, Kulturhistorischen Museum, 2009), Mayence, 2009

\section{Bruno Klein}

\section{OpenEdition}

\section{Journals}

Édition électronique

URL : http://journals.openedition.org/perspective/2792

DOI : $10.4000 /$ perspective. 2792

ISSN : 2269-7721

Éditeur

Institut national d'histoire de l'art

Référence électronique

Bruno Klein, "Aufbruch in die Gotik: Der Magdeburger Dom und die späte Stauferzeit, Landesausstellung Sachsen-Anhalt aus Anlass des 800. Domjubiläums, 2 vol., Matthias Puhle éd., (cat. expo., Magdeburg, Kulturhistorischen Museum, 2009), Mayence, 2009 », Perspective [En ligne], Comptes rendus, mis en ligne le 05 août 2013, consulté le 01 octobre 2020. URL : http://journals.openedition.org/perspective/ 2792 ; DOI : https://doi.org/10.4000/perspective. 2792 


\section{Aufbruch in die Gotik: Der Magdeburger Dom und die späte Stauferzeit, Landesausstellung Sachsen-Anhalt aus Anlass des 800. Domjubiläums, 2 vol., Matthias Puhle éd., (cat. expo., Magdeburg, Kulturhistorischen Museum, 2009), Mayence, 2009}

Bruno Klein

\section{RÉFÉRENCE}

Aufbruch in die Gotik: Der Magdeburger Dom und die späte Stauferzeit, Landesausstellung Sachsen-Anhalt aus Anlass des 800. Domjubiläums, 2 vol., Matthias Puhle éd., (cat. expo., Magdeburg, Kulturhistorischen Museum, 2009), Mayence, 2009. 
1 Après l'incendie de la cathédrale ottonienne de Magdeburg en 1207, on posa la première pierre de la reconstruction en 1209. Cette date a été l'occasion d'organiser une exposition permettant de replacer ce chantier dans un contexte culturel plus large. Elle a dressé un vaste panorama richement illustré, avec des objets allant de la dépouille du chapiteau de l'ancienne cathédrale aux objets de la vie quotidienne, en passant par les palimpsestes de Reims et de nombreux exemples d'enluminure contemporaine. Le présent recueil s'articule en trois axes principaux. Il s'agit d'abord d'examiner la tension entre l'ancienne et la nouvelle

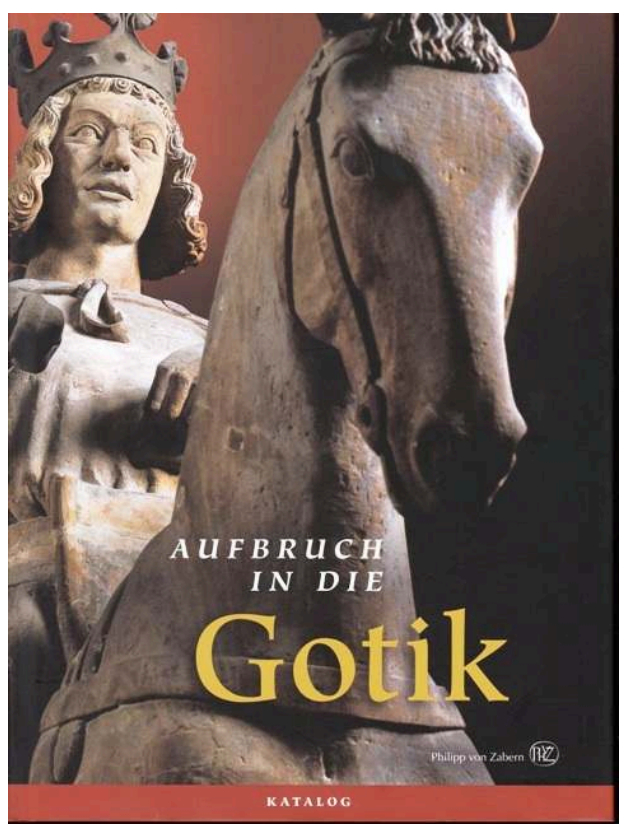
cathédrale, puisque la première construction $\mathrm{du} \mathrm{x}^{\mathrm{e}}$ siècle fut un monument qui devait manifestement générer une identité historique par l'intégration de vestiges antiques. Pour la nouvelle construction de la première moitié $\mathrm{du} \mathrm{XIII}^{\mathrm{e}}$ siècle, on n'y prêta initialement pas attention, puisqu'on se calqua sur le style et la typologie de l'architecture internationale la plus moderne de l'époque. On ne tint même pas compte de l'axe de l'ancien édifice. Mais des doutes subsistent cependant quant à la désignation de "départ vers le gothique » de cette innovation, comme le propose le titre de l'exposition. En effet, ce premier projet fut rapidement soumis à des modifications qui intégrèrent les fragments des colonnes antiques dans la nouvelle construction. Ces études sont complétées par des questions relatives à la continuité de la liturgie et des memoria : l'empereur Otto I et son épouse Edgitha furent notamment enterrés dans la cathédrale. Les sections suivantes de l'ouvrage sont consacrées à la diffusion du savoir au XIII ${ }^{\mathrm{e}}$ siècle ainsi qu'au contexte culturel et politique. Un volume issu du colloque qui accompagna l'exposition, organisé en 2009 à Magdebourg, est en cours de préparation. Un autre ouvrage est paru presque au même moment que le présent catalogue: Harald Meller, Wolfgang Schenkluhn, Boje E. Hans Schmuhl éd., Aufgedeckt, II, Forschungsgrabungen am Magdeburger Dom 2006-2009, Halle (Saale), 2009. Accompagné d'une riche documentation des plans des fouilles et d'un $\mathrm{CD}$, cet ouvrage rassemble principalement les résultats actuels des fouilles portant sur l'édifice qui précédait la cathédrale d'aujourd'hui, des résultats qui attendent toujours d'être interprétés. 